\title{
Impact of Wind Energy System Integration on the Al-Zawiya Refinery Electric Grid in Libya
}

\author{
Akram Gawedar, R. Ramakumar \\ School of Electrical and Computer Engineering, Oklahoma State University, Stillwater, USA \\ Email: Gawedar@okstate.edu
}

How to cite this paper: Gawedar, A. and Ramakumar, R. (2016) Impact of Wind Energy System Integration on the Al-Zawiya Refinery Electric Grid in Libya. Journal of Power and Energy Engineering, 4, 11-20.

http://dx.doi.org/10.4236/jpee.2016.49002

Received: August 8, 2016

Accepted: September 2, 2016

Published: September 5, 2016

Copyright $\odot 2016$ by authors and Scientific Research Publishing Inc. This work is licensed under the Creative Commons Attribution International License (CC BY 4.0).

http://creativecommons.org/licenses/by/4.0/ (c) (i) Open Access

\begin{abstract}
Libya is an oil exporting country located in the middle of the North Africa. Exporting oil is the major income resource for the economics of the country. Al-Zawea refinery is one of the oil refineries in Libya. It is the largest refinery in the region. The refinery located in the Mediterranean coast. Electricity is the main sector in the refinery to produce and export oil. This paper discusses the possibility of the penetration of the renewable energy (wind) generated electricity into the refinery power system. Although, renewable energy application in Libya was started in the middle of the seventies, it has still not found its way into industry sector. This study proposes the possible impacts of renewable (wind) energy system integration on the Al-Zawea refinery electric grid to satisfy the refinery load demand.
\end{abstract}

\section{Keywords}

Libya, Renewable Energy, Wind Speed, Al-Zawea Refinery, Weibull Model, Smart Grid, Distributed Generation

\section{Introduction}

Recently, renewable energy technologies have accelerated around the globe. Increasing the proportion of electricity generated from renewable sources is one of the viable ways to reduce the reliance on fossil fuels and reduce greenhouse gas emissions for clean environment [1]. Currently conventional generation plays a pivotal role in maintaining the power balance between generation and demand. Entry of renewable generation will require a major upgrade of the existing utility system leading to its evolution as a "Smart" grid. Smart grids have become high priority in the industry agenda in many countries around the world. The concept of "Smart grid" is to allow utility to move electricity around the system as efficiently and economically as possible. This study discusses the main features of the smart grid which is distributed generation integration 
to improve system reliability and efficiency. The source of distributed generation considered is the renewable wind energy. Libya is one of the richest countries in the region in wind and solar recourses. The daily average of solar radiation on a horizontal plane is $7.1 \mathrm{kWh} / \mathrm{m}^{2}$ in the coastal region and $8.1 \mathrm{kWh} / \mathrm{m}^{2}$ in the southern region, with daylight duration of more than 3500 hours per year. Wind potential is also very high in many regions and sites in Libya and can contribute to the energy scenario to increase the efficiency and reliability of the current power system [2] [3]. Renewable energy became a very promising research area in last few decades due to its advantages of being able to be integrated with the existing power system in Libya. Since the Al-Zawea refinery is connected to the Libyan national electrical grid, a study of renewable energy penetration into Al-Zawea refinery is considered in this paper. The objective of this study is to investigate the impact of the penetration of renewable energy system (Wind Turbine) on the Al-Zawea refinery power system with reference to voltage profile improvement and system reliability.

\section{Al-Zawea Refinery}

Al-Zawea Refinery is located in Libya, at about 40 kilometers $(25 \mathrm{mi})$ west of the capital city (Tripoli). The refinery was opened in 1974 and it currently produces an estimated 120,000 barrels $\left(19,000 \mathrm{~m}^{3}\right)$ of oil products per day (bpd).

\section{Al-Zawea Refinery Power System}

The refinery has its own power plant and this power plant is connected to the national grid by two $31.5 \mathrm{kV}$ feeders and the electrical distribution network of the refinery is connected to the national grid by a $6.6 \mathrm{kV}$ bus-bar system, as represented in Figure 1 with the following sources.

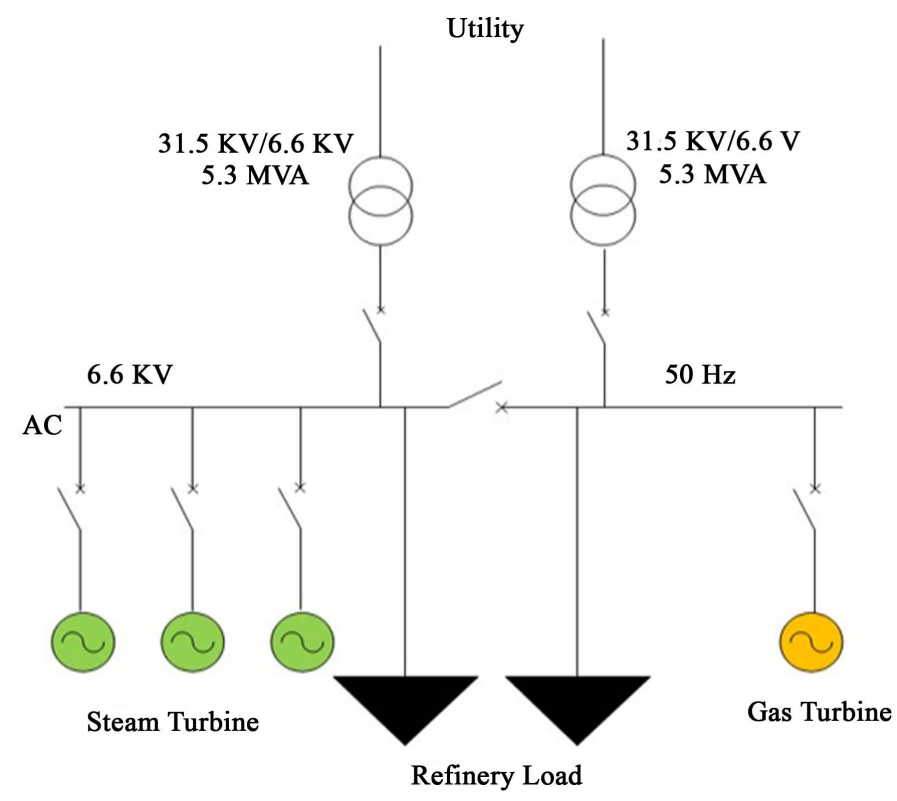

Figure 1. One-line diagram of the Al-Zawea refinery power system. 
- Three steam turbine $6.6 \mathrm{kV}, 6 \mathrm{MVA}$ each.

- One gas turbine generator $6.6 \mathrm{kV}, 23.75 \mathrm{MVA}$.

- Two incoming $6.6 \mathrm{kV}$ cable feeders from $31 \mathrm{kV} / 6.6 \mathrm{kV} 2 \times 10 \mathrm{MVA}$ substation.

The total power demand of the refinery is about $11 \mathrm{MW}-12 \mathrm{MW}$ and it is supplied by:

1. Two steam turbines with $2.5 \mathrm{MW}-3 \mathrm{MW}$ power output (the third in standby).

2. The $6.6 \mathrm{kV}$ incoming cable feeders.

3. The gas turbine generator with a $5 \mathrm{MW}-6 \mathrm{MW}$ output.

Other energy resources can be integrated into the existing power system of the refinery represented by wind energy to reduce the generation cost and ensure clean environment. Proposed system with wind integration is illustrated in Figure 2.

The installation of a number of wind turbine generators can effectively reduce environmental pollution fossil fuel consumption and the cost of overall electricity generation.

\section{Wind Energy}

Wind power is one of the cleanest and most abundant forms of renewable energy. The Impact of wind power integration on the system depends on the size of the power system and the penetration level. Changing wind conditions will affect the power output generated by wind turbines. However, it is technically possible to integrate fairly large amounts (up to 50\%) of wind capacity in power systems. Wind energy resources are available in many regions in Libya in reasonable quantities; preliminary studies indicate that it can be economically exploited [4]. Al-Zawea is a city in northwestern Libya, situated on the Libyan coastline of the Mediterranean Sea about $45 \mathrm{~km}$ west of Tripoli [5] [6]. The electrical consumption of Al-Zawea refinery is about $11 \mathrm{MWh}-12 \mathrm{MWh}$. A part of this demand can be met by wind distributed generation, since wind potential is plentiful in many areas around the refinery.

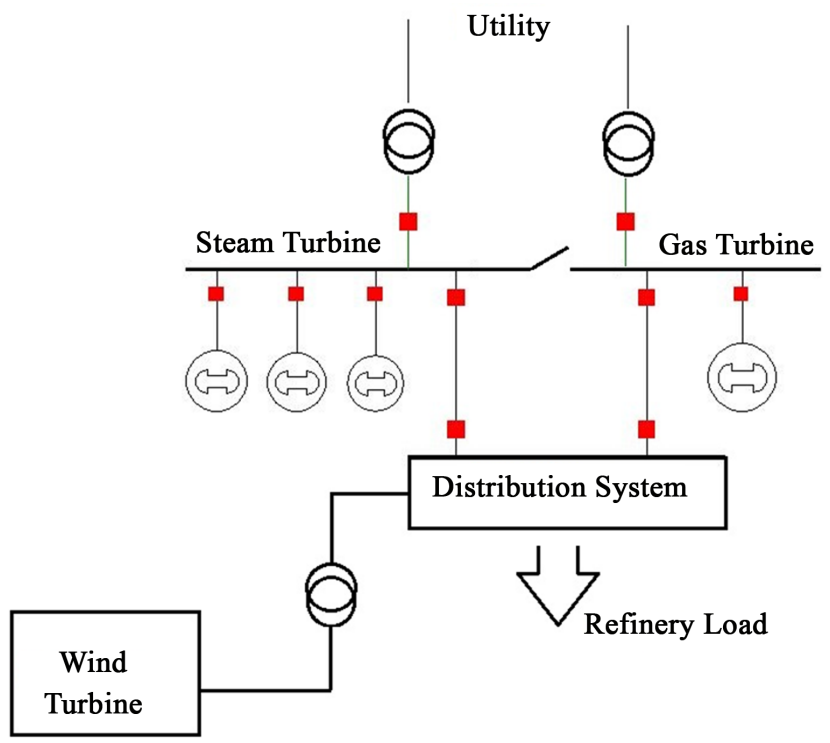

Figure 2. One-line diagram of the Al-Zawea refinery power system with wind power system. 


\subsection{Wind Speed Data Energy}

The geographic location of the study area is Al-Zawea city. It is situated in the North West of Libya on latitude $32.67^{\circ} \mathrm{N}$ and longitude $13.15^{\circ} \mathrm{E}$. It is a coastal region with population of about 1 million people. The wind speed data used for analysis was measured over a period of 16 months by renewable energy authority of Libya (REAOL) from Sep-2002 to Dec 2003 at 10-minute intervals with mast height of $30 \mathrm{~m}$. The monthly average of wind speed is summarized in Table 1 and illustrated in Figure 3.

Typically, there are two basic ways at present to evaluate wind power and investigate the feasibility of the wind energy resource at any site. The first method is based on measured values that are recorded at meteorological stations. The second method is to assess wind power potential by using probability distribution functions [7]. In this study, the Weibull distribution is employed for wind power assessment as presented and discussed in the following section.

\subsection{Weibull Model for Wind Speed in Al-Zawea City in Libya}

Probability density and distribution functions are used to evaluate the energy production from wind turbines and to describe random variations of wind speed. Weibull distribution function has been widely used, accepted and recommended to model wind

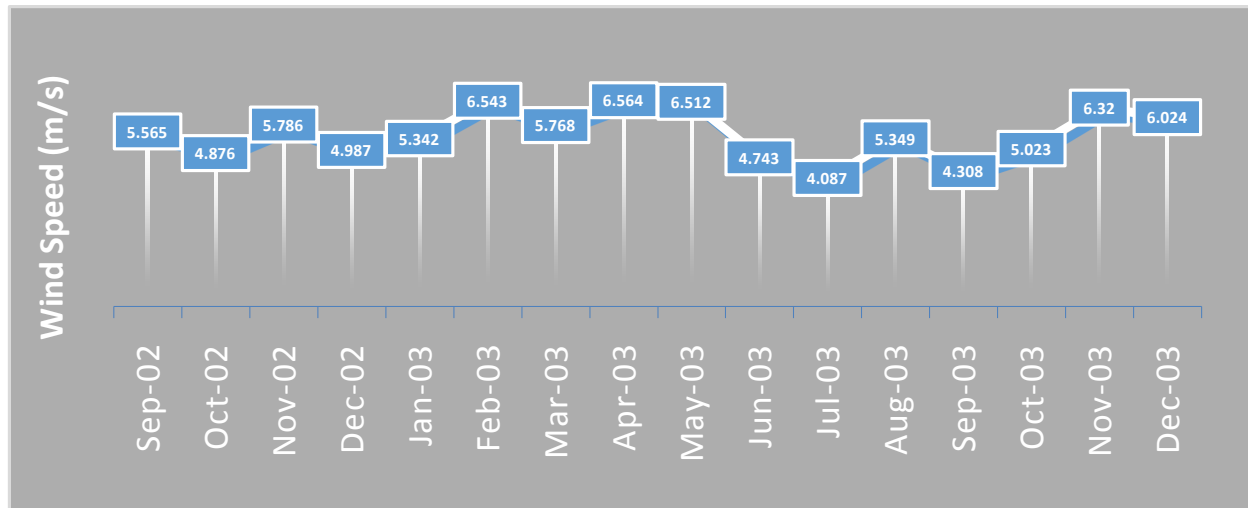

Figure 3. Average wind speed values $(\mathrm{m} / \mathrm{s})$ in Al-Zawea $(1 \mathrm{~m} / \mathrm{s}=2.237 \mathrm{mph})$.

Table 1. Monthly average wind speed values $(\mathrm{m} / \mathrm{s})$ in Al-Zawea Libya.

\begin{tabular}{cccc}
\hline Month & $\bar{v}$ & Month & $\bar{v}$ \\
\hline Sep-2002 & 5.565 & May-2003 & 6.512 \\
Oct-2002 & 4.876 & Jun-2003 & 4.743 \\
Nov-2002 & 5.786 & Jul-2003 & 4.087 \\
Dec-2002 & 4.987 & Aug-2003 & 5.349 \\
Jan-2003 & 5.342 & Sep-2003 & 4.308 \\
Feb-2003 & 6.543 & Oct-2003 & 5.023 \\
Mar-2003 & 5.768 & Nov-2003 & 6.32 \\
Apr-2003 & 6.564 & Dec-2003 & 6.024 \\
\hline
\end{tabular}


speed and estimate wind energy potential. The Weibull density function is a two-parameter function characterized by a dimensionless shape parameter $(\beta)$ and scale parameter $(\alpha)$ in $(\mathrm{m} / \mathrm{s})$. These two parameters are determining the wind speed for optimum performance of a wind conversion system as well as the wind speed range over which the device is likely to operate [8] [9]. The probability density function is given by:

$$
f(v)=\left(\frac{\beta}{\alpha}\right)\left(\frac{v}{\alpha}\right)^{\beta-1} \exp \left(-\left(\frac{v}{\alpha}\right)^{\beta}\right)
$$

where $f(v)$ is the probability density function for the random variable wind speed $(v) ; \beta$ is a dimensionless Weibull shape parameter and $\alpha$ is a scale parameter of wind speed $(\mathrm{m} / \mathrm{s})$. There are several ways to estimate a Weibull PDF to fit wind speed distribution [7]. The most widely used methods to calculate the Weibull parameters are the following:

1. Graphical method (GM).

2. Moment method (MM).

In this study the graphical method (GM) and moment methods (MM) are employed.

- Graphical method (GM): this method requires the wind speed data be in cumulative frequency distribution format represented by straight line, with the shape factor $\beta$ as a slope of the straight-line (GM) results represented by Figure 4 . From the relevant following equations:

$$
\begin{gathered}
\{1-F(v)\}^{-1}=\mathrm{e}^{\left(\frac{v}{\alpha}\right)^{\beta}} \\
-\ln \{1-F(v)\}=k \ln v-k \ln \alpha
\end{gathered}
$$

The shape parameter $\beta$ and scale parameter $\alpha$ are calculated for Al-Zawiya Libya based on daily average wind speed data.

- Moment Method (MM): In this method, the parameters $\beta$ and $\alpha$ are determined by the following equations:

$$
\begin{gathered}
\bar{v}=\alpha \Gamma\left(1+\frac{1}{\beta}\right) \\
\sigma=\alpha \sqrt{\Gamma(1+2 / \beta)-\Gamma^{2}(1+1 / \beta)}
\end{gathered}
$$

where $\Gamma$ is gamma function $\bar{v}$ and $\sigma$ are the mean wind speed and the standard deviation of the observed data of the wind speed respectively.

The shape parameter $\beta$ and scale parameter $\alpha$ for the Weibull distributed function are calculated for Al-Zawea in Libya by graphical method (GM) and moment method (MM) the obtained parameters are listed in Table 2.

The analysis of AL-Zawea wind data patterns shows that wind speed in the location of the refinery can provide a good wind power for renewable energy applications such as distributed wind energy system. Since the wind is a free while, fuel oil and natural gas are not. Reduce the cost and emission of $\mathrm{CO}_{2}$ can be achieved as the major object- 

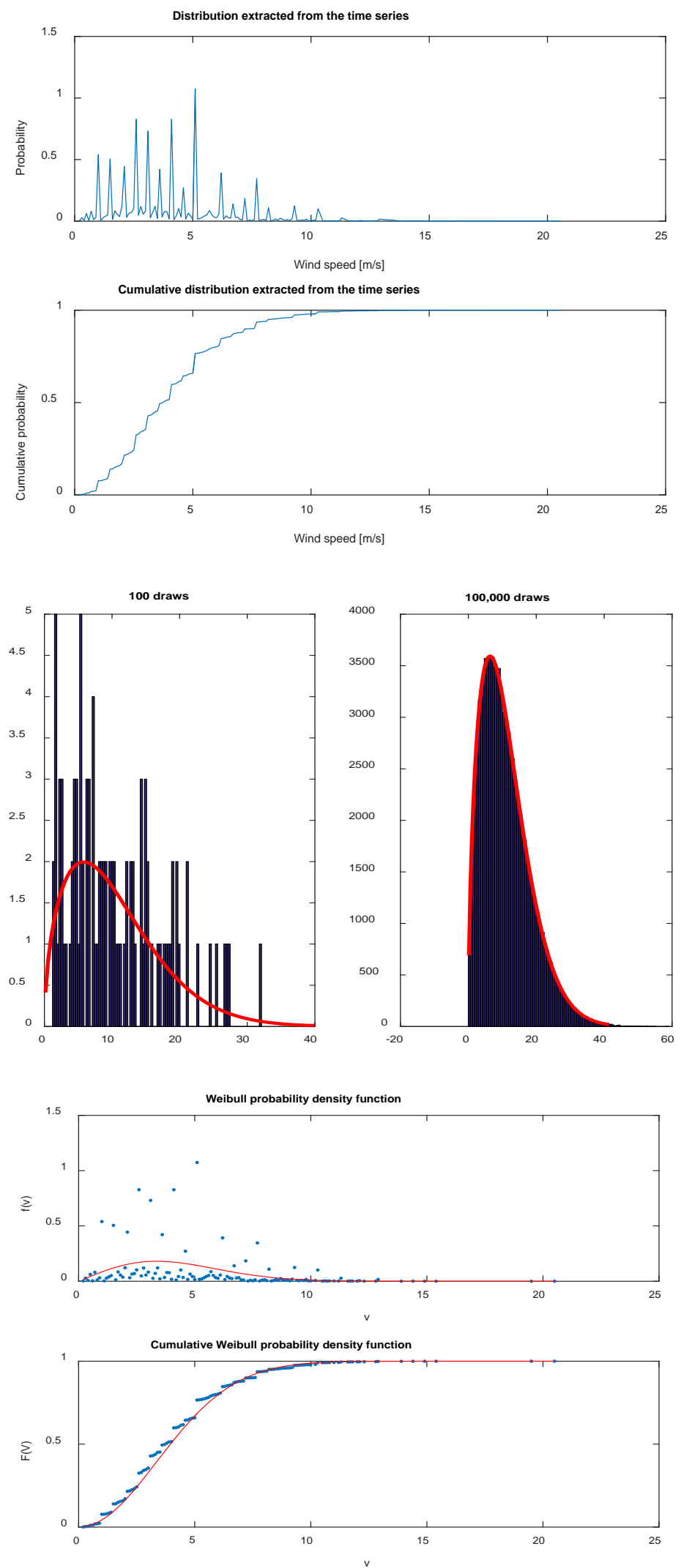

Figure 4. Results of Weibull distribution functions parameters by using GM. 
Table 2. The Weibull parameters $\beta$ and $\alpha$.

\begin{tabular}{ccc}
\hline Weibull parameters & GM & MM \\
\hline$\beta$ & 2.0027 & 2.1204 \\
$\alpha$ & 4.7494 & 4.8931 \\
\hline
\end{tabular}

tives of integrate renewable energy system into the existing system at Al-Zawea refinery power system.

\section{Voltage Profile Improvement}

The existing distributed system of the Al-Zawea refinery power system shows by Figure 5. In this study, integration of wind power generation into the Al-Zawea refinery power system is considered, several scenarios were investigated by integrate wind power into the existing power system in the refinery and study the power flow with the stability of the proposed system and evaluate the voltage profile of the system.

\section{Discussion of Simulation Results}

Distributed generators (wind turbines) were scattered throughout the existing distribution system at AL-Zawea refinery to provide a demand power for the load. Additional distribution lines were added to the system connecting the DG to the buses near critical loads. Varying percentages of wind power penetration have been considered from the total power generation under various scenarios. The Power World simulator and Matlab software were used to simulate the system. The entire system comprises of 25 Buses and load data, distribution line parameters and bus voltages are used as input data to conduct the study. A load flow analysis is run considering the different scenarios, the performance evaluation of the proposed system done by comparing every scenario with the base scenario based on voltage profile (p.u voltages for each bus). The base scenario has no wind turbines. The results of the simulation are illustrated in Figure 5. X-axis shows bus numbers and Y-axis shows p.u voltages for each bus in the system. The three scenarios for proposed system are explained in the following points:

- Scenario 1: A wind power of $20 \%$ (2.4 MW) of the total power generation was added to the system with mean wind speed $(6.3 \mathrm{~m} / \mathrm{s})$. Figure 6 shows the results obtained from the simulation of the Al-Zawea refinery power system with wind power. As Figure 6 shows, adding wind power to the system with $20 \%$ of wind power generation from the total generation provides a good voltage profile.

- Scenario 2: A wind power generation of $35 \%$, which is $4.2 \mathrm{MW}$ added to the total power generation of the refinery power generation, was integrated into the existing power system. As shown in Figure 7 the voltage profile has a good result.

- Scenario 3: The third scenario 50\% (6 MW) added to the total power generation in the refinery was replaced by wind power generation. Figure 8 shows the results obtained by simulation of the AL-Zawea refinery power system with wind power generation. It is clear as the Figures show that, adding wind power to the system can improve the voltage profile. 


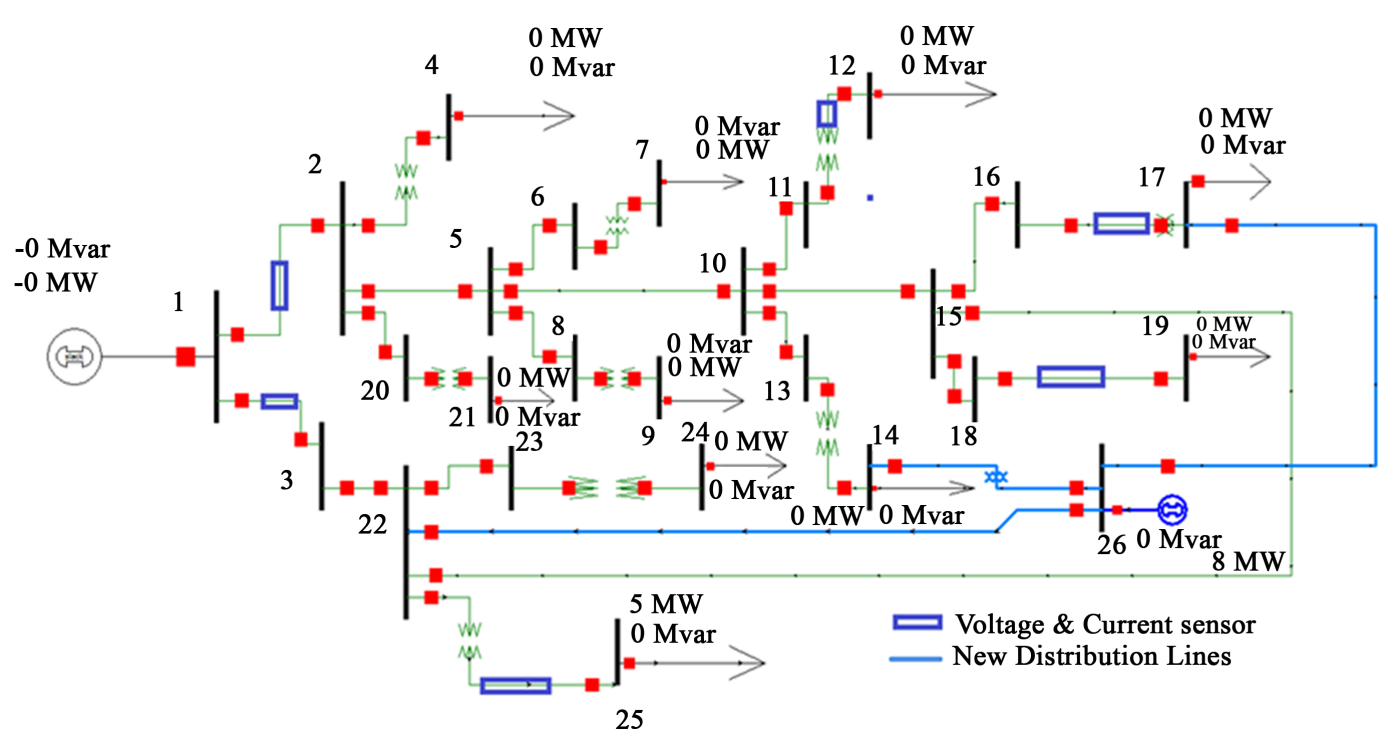

Figure 5. A segment of the distributed system with proposed DG.

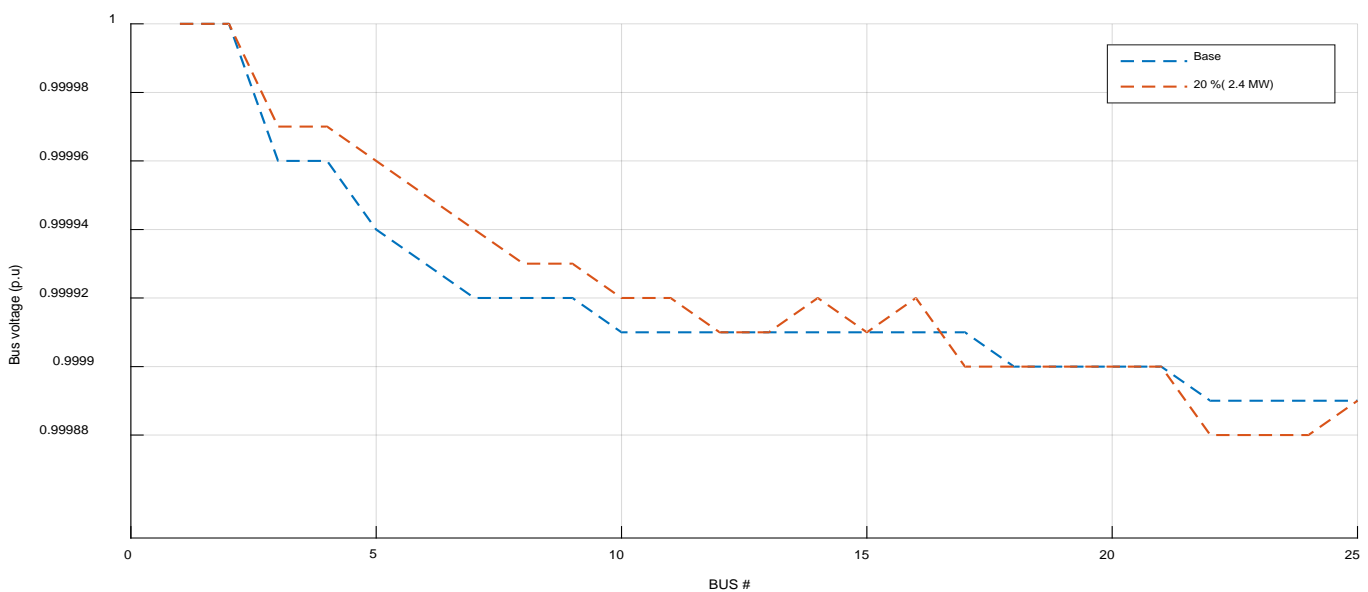

Figure 6. Simulation result of voltage profile for Scenario 1.

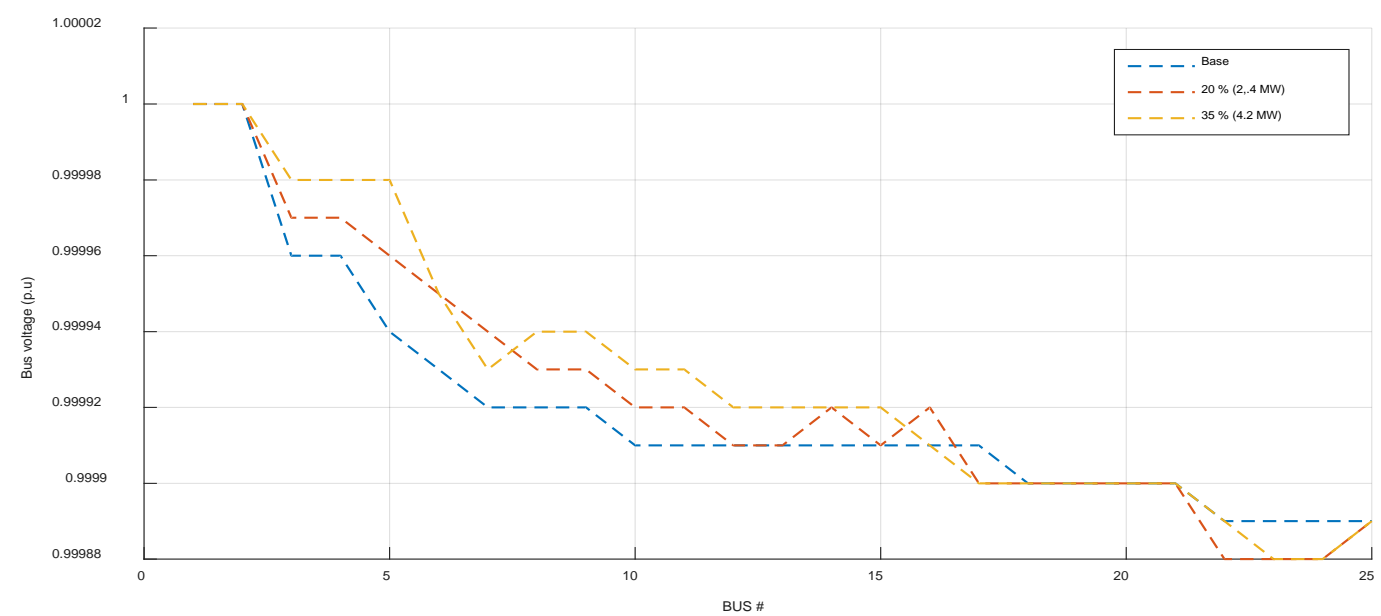

Figure 7. Simulation result of voltage profile for Scenario 2. 


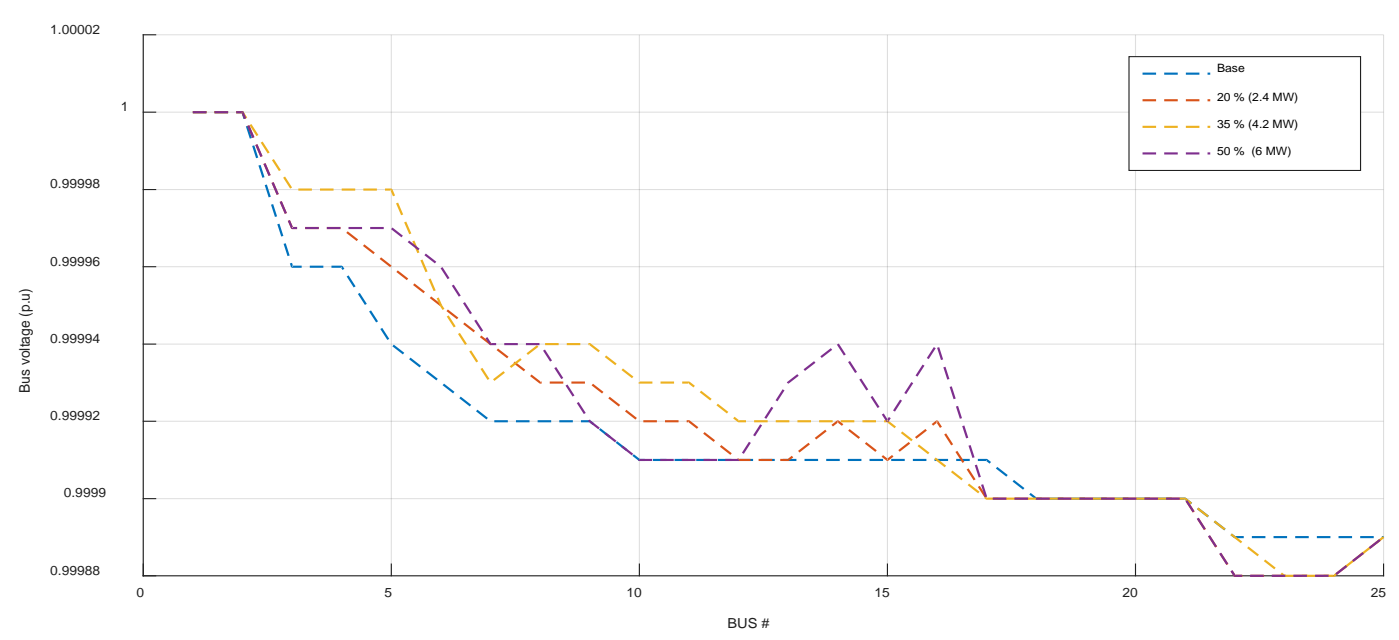

Figure 8. Simulation result of voltage profile for Scenario 3.

\section{Conclusion}

The transition towards a smart system (Smart Grid) from the existing power system at the Al-Zawea refinery can be justified to meet the system reliability and efficiency by adding renewable energy generation (wind energy) to the system. This study presents an analysis of wind speed data using fitting curve methods to obtain the parameters of the Weibull density function. The associated scale and shape parameters were obtained from the two different methods GM and MM which have showed that the location of the refinery had a potential of wind that could be invested to generate the power. Varying percentages of wind power generation added to the existing system for simulation purposes. From the results, it was found that the voltage profile p.u of the entire system gave a good result and kept the system stable with the addition of wind-generated energy. This approach has the added advantage of reducing $\mathrm{CO}_{2}$ emission and improving the overall economics.

\section{Acknowledgements}

This work was supported by the Oklahoma State University Engineering Energy Laboratory in the School of Electrical and Computer Engineering and financially supported by the Libyan government.

\section{References}

[1] Neuhoff, K. (2005) Large-Scale Deployment of Renewables for Electricity Generation. $O X$ ford Review of Economic Policy, 21, 88-110. http://dx.doi.org/10.1093/oxrep/gri005

[2] Saleh Ibrahim, I.M. (1993) The 4th Arab International Solar Energy Conference "Comparative Study in Supplying Electrical Energy to Small Remote Loads in Libya”. Amman, Jordan.

[3] Saleh Ibrahim, M. (2011) Photovoltaic in Libya Applications, and Evaluation. General Electrical Company of Libya.

[4] (2015) General Electric Company of Libya (GECOL) Annual Report. 
[5] (2016) 11:05 PM, 8/26/16. https://en.wikipedia.org/wiki/Zawiya,_Libya

[6] http://windenergyfoundation.org/about-wind-energy/

[7] Azad, A.K. (2014) Statistical Diagnosis of the Best Weibull Methods for Wind Power Assessment for Agricultural Application. Energies Journal, 7.

[8] Lun, I.Y.F. and Lam, J.C. (2000) A Study of Weibull Parameters Using Long-Term Wind Observations. Renewable Energy, 20, 145-153.

http://dx.doi.org/10.1016/S0960-1481(99)00103-2

[9] Odo, F., Offiah, S. and Ugwuoke, P. (2012) Weibull Distribution-Based Model for Prediction of Wind Potential in Enugu, Nigeria. Advances in Applied Science Research, 3, 12021208.

Submit or recommend next manuscript to SCIRP and we will provide best service for you:

Accepting pre-submission inquiries through Email, Facebook, LinkedIn, Twitter, etc. A wide selection of journals (inclusive of 9 subjects, more than 200 journals)

Providing 24-hour high-quality service

User-friendly online submission system

Fair and swift peer-review system

Efficient typesetting and proofreading procedure

Display of the result of downloads and visits, as well as the number of cited articles

Maximum dissemination of your research work

Submit your manuscript at: http://papersubmission.scirp.org/ 